\title{
LETTER
}

\section{Polymorphic Forms of Chocolate: Application of Solid-State Characterization in the Food Industry}

\author{
Renan Marcel Bonilha Dezena (iD $ه$ \\ Preformulation Specialist in the Pharmaceutical Industry
}

\section{Background}

Polymorphism is very well discussed and consolidated in the pharmaceutical industry related to the impact on formulations and manufacture process; however, it is also an extremely important topic for the field of the chemical food industry [1-5].

Analytical characterization techniques, including X-ray diffraction, differential scanning calorimetry, thermogravimetric analysis, confocal Raman microscopy, laser diffraction, and spectroscopic approaches for structural characterization of food products are powerful tools [1-5].

Chocolate is one of the best-selling products in the food industry worldwide [6-8]. The type of chocolate manufacturing process used will interfere with consumers' perception and taste [9]. The perception of chocolate palate is directly related to the crystallographic structure, particle size range $(0.01 \mathrm{~mm}$ to $0.1 \mathrm{~mm}$ ), geometry and spatial arrangement [9]. Cocoa butter (CB), a key ingredient in chocolate, has six polymorphs characterized, that is, the same molecule with other crystallographic arrangements, thus influencing the physicochemical properties in chocolate, such as melting, strength, shine, texture and flavor [9]. Several studies are being conducted to elucidate and improve knowledge related to the complexity of CB polymorphism [9]. There are many studies published in the literature on the impact of molecular structure and lipid polymorphism on macroscopic aspects; however, they did not consider the microstructure of the network [10].

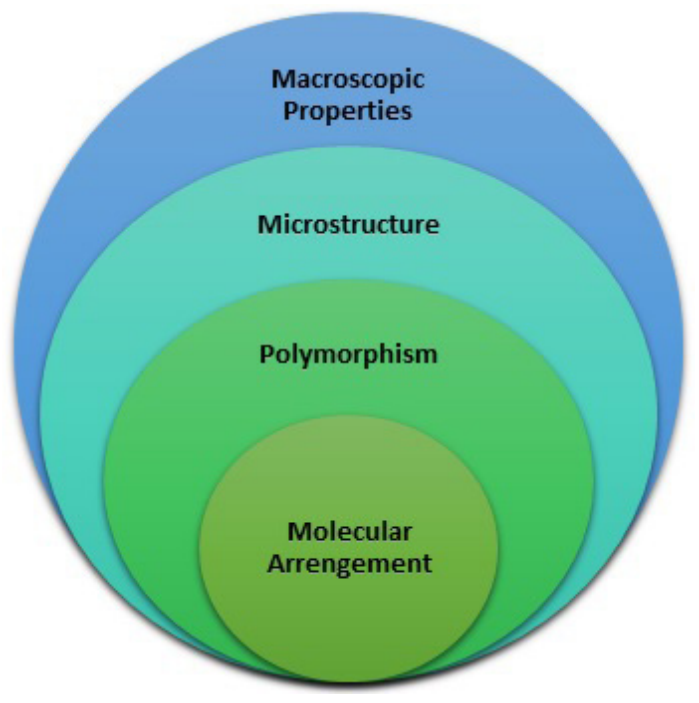

Figure 1. Schematic representation of the influence of the crystallographic profile of fats on macroscopic attributes [10].

Cite: Dezena, R. M. B. Polymorphic Forms of Chocolate: Application of Solid-State Characterization in the Food Industry. Braz. J. Anal. Chem., 2021, 8 (30), pp 11-13. doi: http://dx.doi.org/10.30744/brjac.2179-3425.letter-rmbdezena-N30 
The chemical profile of CB can be affected based on the refinement process and the type of source used, thus being able to influence the crystallization rate and stability. Regarding the microstructural aspect, the polymorphism of cocoa butter affects the shape, size and melting point of the crystal. The alpha $(\alpha)$, beta prime $\left(\beta^{\prime}\right)$ and beta $(\beta)$ polymorphs were determined by crystallographic and thermal analysis being classified in increasing order of stability, respectively. These three polymorphs differ in physical properties, but mainly with respect to the melting point [10].

- The $\beta$ polymorph, which is the most stable, has a triclinic crystal system with a typical short spacing pattern of $4.6 \AA$. The $\beta^{\prime}$ form is an orthorhombic structure with 3.8 and $4.2 \AA$ [10].

- The $\alpha$ form, which is the less stable, is a hexagonal arrangement with $4.15 \AA$. In some studies, other metastable forms, called $\gamma$ and $\delta$, and $\beta^{\prime}$ have been found [10].

- Polymorph $\mathrm{Y}$, like polymorph $\beta^{\prime}$, is an orthorhombic perpendicular system with short spacing characteristics of 3.8 and $4.2 \AA$ [10].

Approaching and understanding the mechanisms of polymorphic transitions of natural fats is not a simple task due to the complexity of the sample matrix. An example would be $\mathrm{CB}$, in which six polymorphic forms were elucidated, however, the nomenclature of these forms is not harmonized [10].

Chocolate companies describe polymorphic forms as I-VI, in increasing order of stability. Margarine and fat companies use the nomenclature $y$ (or sub- $\alpha$ ), $\alpha, \beta^{\prime} 2, \beta^{\prime} 1, \beta 2$ and $\beta 1$, in increasing order of stability, as well [10].

Regarding the taste, texture and brightness, among the abovementioned polymorphs, it was proven that form $\mathrm{V}$ presents greater efficiency and quality in chocolates, in addition to melting in the mouth at the temperature of the human organism [9]. Tables I and II show some of the properties of CB polymorphs.

Table I. Melting point and preparation of cocoa butter polymorphs according to the nomenclature of chocolate companies [11]

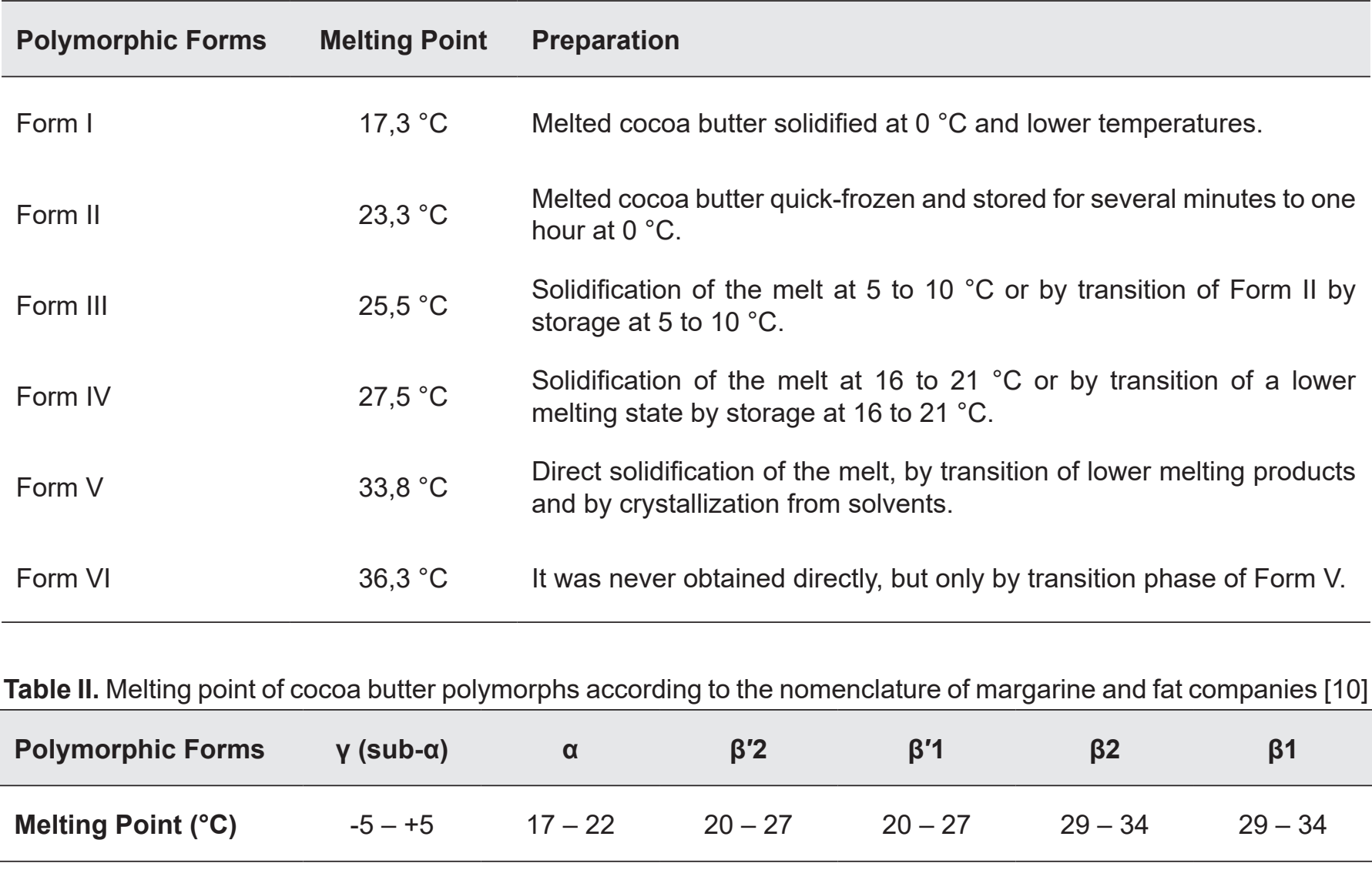




\section{SUMMARY}

Solid state characterization is fundamental for developing food products enabling better knowledge regarding formulation performance, processability, stability and functionality; promoting quality and safety to costumer, to meet regulatory standards.

\section{REFERENCES}

1. Dezena, R. M. B. Braz. J. Anal. Chem., 2017, 4 (16), pp 8-9.

2. Dezena, R. M. B.; Malta Jr., J. D. S. Braz. J. Anal. Chem., 2017, 4 (15), pp 19-26.

3. Dezena, R. M. B.; Malta Jr., J. D. S.; Meurer, E. C.; Eberlin, M. N. Braz. J. Anal. Chem., 2017, 4 (15), pp 27-34.

4. Dezena, R. M. B. Braz. J. Anal. Chem., 2020, 7 (26), pp 12-17 (http://dx.doi.org/10.30744/ brjac.2179-3425.letter.rmbdezena.N26).

5. Dezena, R. M. B.; Malta Júnior, J. S.; de Godoy, F. P.; Smith, T. Braz. J. Anal. Chem., 2020, 7 (28), pp 11-19 (http://dx.doi.org/10.30744/brjac.2179-3425.N28-letter).

6. Montagna, M. T.; Diella, G.; Triggiano F.; Caponio, G. R.; De Giglio, O.; Caggiano, G.; Di Ciaula, A.; Portincasa, P. Int. J. Environ. Res. Public Health., 2019, 16 (24), pp 1-21 (https://doi.org/10.3390/ ijerph16244960).

7. Massot-Cladera, M.; Pérez-Cano, F.; Llorach, R.; Urpi-Sarda, M. Nutrients, 2017, 9 (2), pp 1-31 (https:// doi.org/10.3390/nu9020156).

8. Lippi, D. Nutrients, 2013, 5 (5), pp 1573-84 (https://doi.org/10.3390/nu5051573).

9. Ek, C. H.; Kragic, D. The Importance of Structure. In: Christensen, H.; Khatib, O. (Eds.). Robotics Research. Springer Tracts in Advanced Robotics, vol 100. Springer, Cham., 2017, pp 111-127 (https:// doi.org/10.1007/978-3-319-29363-9_7).

10. McGauley, S. E.; Marangoni, A. G. Static Crystallization Behavior of Cocoa Butter and Its Relationship to Network Microstructure. In: Marangoni, A. G.; Narine, S. (Eds.). Physical Properties of Lipids. First edition. New York: Marcel Dekker, Inc., 2002, pp 94-130.

11. Wille, R. L.; Lutton, E. S. J. Am. Oil Chem. Soc., 1966, 43 (8), pp 491-496 (https://doi.org/10.1007/ BF02641273).

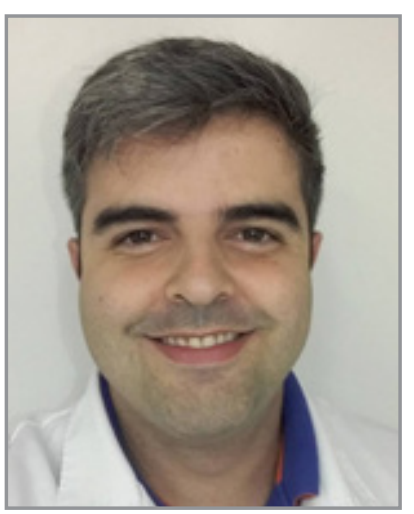

Renan M. B. Dezena is a Preformulation Specialist with Graduation in Pharmaceutical Sciences from Pontifical Catholic University of Campinas (PUC-Campinas), Brazil (2010), and Specialization in Management of Research and Development of Drugs through the Institute of Sciences, Technology and Quality (ICTQ), Brazil (2014). He has 11 years of experience in the Pharmaceutical Industry with background in the Departments of Production, Quality Control and Research \& Development. Perform Preformulation Studies related to the development of pharmaceutical products through the following analytical techniques: Mass spectrometry (LC-MS/MS), Infrared Spectroscopy (MIR and NIR), Ultraviolet Spectroscopy, Liquid Chromatography (HPLC and UPLC), Gas Chromatography (GC-MS), Differential Scanning Calorimetry (DSC), Thermogravimetric Analysis (TGA), X-Ray Powder Diffraction (XRPD), Optical Microscopy, Particle Size Distribution by Laser Diffraction, Confocal Raman Microscopy, Nuclear Magnetic Resonance Spectroscopy, Zeta Potential and Dynamic Light Scattering. 